\title{
Comparison of Mastication Status in Ameloblastoma Patients Post-Mandibular Segmental Resection Operation with LC Type with Mandibular Reconstruction using Plate And Plate Bone Graft in RSUD Dr. Soetomo
}

\author{
Djoko Supriyandono*, Marjono Dwi Wibowo**, Dwi Hari Susilo**, Sahudi** \\ *General Surgery Resident, Faculty of Medicine, Airlangga University / RSUD Dr. Soetomo Surabaya \\ **SMF / Lab Teaching Staff. Surgery Faculty of Medicine, Airlangga University / Dr. Soetomo Surabaya
}

Corresponding Author: Djoko Supriyandono

\begin{abstract}
Background: Mandibular resection is part of the surgical operation for ameloblastoma cases, followed by mandibular reconstruction. Good masticatory status should be taken into account in determining the success of mandibular reconstruction. To assess mastication, some measuring instruments in the form of a questionnaire were created, one of which is the Tsuga questionnaire. At RSUD Dr. Soetomo Surabaya, the most common resection performed is mandibular segmental resection with an LC type defect, where an assessment of mastication status had not been carried out in this case.

Methods: This study is an analytic study to see the mastication status of patients after mandibular resection and reconstruction with a case-control study design. This study used primary data in the form of interviews and secondary data in the form of medical records of ameloblastoma patients who had undergone mandibular resection surgery with an LC type defect and underwent mandibular reconstruction at RSUD Dr. Soetomo Surabaya.
\end{abstract}

Results: The total research subjects were 50 people, consisting of 26 men (52\%) and 24 women (48\%). From the results of the study, there was no statistically significant relationship between the age group and mastication status after mandibular reconstruction ( $\mathrm{p}$-value = $0.765)$ and also between gender and mastication status after mandibular reconstruction $(\mathrm{p}$-value $=$
0.725). Meanwhile, between the type of reconstruction and mastication status, there was a statistically significant relationship $(\mathrm{p}$-value $=$ 0.011 ). It was also found that patients with the type of reconstruction using a plate bone graft had five times better mastication status than those who used the type of reconstruction using a plate.

Conclusion: There is a statistically significant relationship between the type of reconstruction and mastication status. Mandibular reconstruction in postoperative ameloblastoma patients with mandibular segmental resection with LC type defects using plate bone graft has a better mastication status than those using plates without bone graft.

Keywords: masticatory status, ameloblastoma, mandibular resection, mandibular reconstruction

\section{INTRODUCTION}

Ameloblastoma is an odontogenic epithelial neoplasm of the mandible originating from the undifferentiated enamel layer with an incidence of 0.6 cases per $1,000,000$ population. The main modality of therapy in ameloblastoma is surgery, of which mandibular resection is one of them. ${ }^{1}$

Mandibular resection is part of a surgical operation for ameloblastoma cases that aims to maintain mandibular function by paying attention to cosmetics. Thus, mastication status must be taken into 
Djoko Supriyandono et.al. Comparison of mastication status in ameloblastoma patients post-mandibular segmental resection operation with LC type with mandibular reconstruction using plate and plate bone graft in RSUD Dr. Soetomo.

account concerning material selection. ${ }^{2}$ After mandibular resection, the patient will experience physiological changes such as deviation, limited lateral movement, impaired protrusion, occlusion, mastication, and articulation which have an impact on changes in appearance, impaired speech, swallowing, chewing which affects their nutritional status, so that mandibular reconstruction is sometimes unsatisfactory and lead to a decrease in the patient's quality of life. ${ }^{3,4}$

At RSUD Dr. Soetomo Surabaya, in medical record data from 2015 to 2018, there were 100 cases of ameloblastoma who underwent mandibular resection and mandibular reconstruction, with mandibular segmental resection with LC type defect being the most frequently performed with a total of 55 cases. Of all cases, patient follow-up was limited to patient surveillance and no postoperative assessment of the patient's mastication status was performed.

Mastication status is currently seen as a measure of the success of mandibular resection and reconstruction. Therefore, it is necessary to assess the masticatory status of the patient after undergoing mandibular segmental resection and mandibular reconstruction. To assess the status of mastication in the form of a questionnaire by health organizations, one of which is the Tsuga questionnaire. ${ }^{5}$

From the results of the study, there was no statistically significant relationship between the age group and post-mandibular mastication status $(\mathrm{p}$-value $=0.765)$ and also between sex and post-mandibular mastication status ( $\mathrm{p}$-value $=0.725$ ). Meanwhile, between the type of reconstruction and mastication status, there was a statistically significant relationship ( $p$-value $=0.011)$. It was also found that patients with the type of reconstruction using a plate bone graft had 5 times better mastication status than those who used the type of reconstruction using a plate.

\section{METHODS}

This study is an analytic study to see the mastication status of patients after mandibular resection and reconstruction with a case-control study design. This study used primary data in the form of interviews and secondary data in the form of medical records of ameloblastoma patients who had undergone mandibular resection surgery with an LC type defect and underwent mandibular reconstruction at Dr. Soetomo Surabaya.

The inclusion criteria in this study included patients who underwent mandibular resection surgery with LC type defects and mandibular reconstruction with plates without bone graft or using plates with bone grafts in the Head-Neck Surgery Division, at least having undergone surgery for more than six months, patients willing to participate in the study as research respondents. While the exclusion criteria included patients experiencing recurrence during the study, patients were unable to fill out the questionnaire because of cognitive impairment such as dementia or language problems, patients had diseases of other head-neck areas, such as parotitis, salivary gland tumors, and thyroid gland tumors and patients had malignant ameloblastoma disease.

\section{RESULTS}

The total research subjects were 50 people, consisting of 26 men (52\%) and 24 women (48\%). Judging from the age of the research subjects, 33 people $(66 \%)$ were 21 40 years old and 17 people were 41-60 years old (34\%). Judging from the type of plate reconstruction as many as 23 people (46\%), and those using plate bone graft reconstruction as many as 27 people (54\%).

Table 1. Characteristic of Subject Research

\begin{tabular}{|l|l|l|l|}
\hline Characteristic & $21-40$ y.o & n & Percentage \\
\hline Age & $\geq 41$ y.o & 33 & $66 \%$ \\
\hline \multirow{3}{*}{ Sex } & Male & 17 & $34 \%$ \\
\cline { 2 - 4 } & Female & 26 & $52 \%$ \\
\hline \multirow{2}{*}{ Reconstruction Type } & Plate & 24 & $48 \%$ \\
\cline { 2 - 4 } & Plate Bone Graft & 23 & $46 \%$ \\
\hline Mastication Status & Good & 25 & $54 \%$ \\
\cline { 2 - 4 } & Bad & 25 & $50 \%$ \\
\hline
\end{tabular}


Djoko Supriyandono et.al. Comparison of mastication status in ameloblastoma patients post-mandibular segmental resection operation with LC type with mandibular reconstruction using plate and plate bone graft in RSUD Dr. Soetomo.

From the data of this study, it was found that most of the research subjects were in the age group of 21-40 years, namely 17 people $(51.5 \%)$ who had good mastication status and as many as 16 people (48.5\%) had poor mastication status. the age group 41 years obtained as many as 8 $(47.06 \%)$ who have good mastication status and who have bad mastication status as many as $9(52.94 \%)$. The characteristics of the age group and mastication status were tested using the Chi-Square test, it was found that there was no relationship between the age group and mastication status with a $\mathrm{p}$-value $=0.765(\mathrm{p}>0.05)$, which means that there is no statistically significant relationship between age and status. Mastication after mandibular reconstruction, with an Odd Ratio value of 1.195, CI: $95 \%$.

Table 2. Relationship of Age to Mastication Status

\begin{tabular}{|l|l|l|l|l|l|}
\hline \multirow{2}{*}{ Age } & Mastication Status & Total & \multirow{2}{*}{ P Value } & OR \\
\cline { 2 - 4 } & Good (\%) & Bad (\%) & & & \\
\hline $21-40$ th & $17(51,5 \%)$ & $16(48,5 \%)$ & $33(100 \%)$ & 0,765 & 1,195 \\
\hline$\geq 41$ th & $8(47,06 \%)$ & $9(52,94 \%)$ & $17(100 \%)$ & & $(95 \%$ \\
\hline Total & $25(50 \%)$ & $25(50 \%)$ & $50(100 \%)$ & & CI: $0,370-3,858)$ \\
\hline
\end{tabular}

From the data of this study, it was found that in most of the research subjects were male as many as 26 people $(100 \%)$ consisting of those who had good mastication status as many as 12 people $(46.2 \%)$ and those who had poor mastication status as many as 14 people (53 people). ,8\%), while in female patients as many as 24 people (100\%) consisting of 13 people $(54.2 \%)$ had good mastication status and 11 people had bad mastication status $(45.8 \%)$. It was found that the majority of males had poor mastication status. The characteristics of sex and mastication status were tested using the Chi-Square test, it was found that there was no relationship between gender and mastication status with a $p$-value $=0.725(p>0.05)$, which means that there is no statistically significant relationship between gender and mastication. Mastication status after mandibular reconstruction, with an odds ratio of $0.725 ; 95 \% \mathrm{CI}$.

Table 3. Relationship of Sex with Mastication Status

\begin{tabular}{|l|l|l|l|l|l|}
\hline \multirow{2}{*}{ Sex } & \multicolumn{2}{|l|}{ Mastication Status } & Total & P Value & OR \\
\cline { 2 - 4 } & Good (\%) & Bad (\%) & & & \\
\hline Male & $12(46,2 \%)$ & $14(53,8 \%)$ & $26(100 \%)$ & 0.008 & 0,725 \\
${ } }$ & $13(54,2 \%)$ & $11(45,8 \%)$ & $24(100 \%)$ & & $(95 \%$ \\
\hline Total & $25(50 \%)$ & $25(50 \%)$ & $50(100 \%)$ & & CI: $0,238-2,208)$ \\
\hline
\end{tabular}

The reconstruction chosen is plate reconstruction with stainless steel, AO plate, Vitallium, and titanium without bone, and plate bone graft using bone, which can be taken from the rib bone or iliac crest. In this study, it was found that most of the research subjects used the type of reconstruction with plate bone graft as many as 27 people $(100 \%)$ consisting of 18 people $(66.7 \%)$ having good mastication status and 9 people having poor mastication status (33.3\%), while the research subjects who used the type of reconstruction with plates obtained as many as 23 people $(100 \%)$ consisting of 7 people (30.4\%) had good mastication status and 16 people $(69.6 \%)$ had bad mastication status.

The characteristics of the reconstruction type on mastication status were tested using the Chi-Square test, it was found that there was a relationship between the type of reconstruction and the status of mastication with a p-value $=0.011(\mathrm{p}<$ 0.05) which means that there is a statistically significant relationship between the type of reconstruction and the status of mastication. And also, it was found that patients with plate bone graft reconstruction had five times better mastication status than those with plate reconstruction $(\mathrm{OR}=4,571$; $95 \% \mathrm{CI})$. 
Djoko Supriyandono et.al. Comparison of mastication status in ameloblastoma patients post-mandibular segmental resection operation with LC type with mandibular reconstruction using plate and plate bone graft in RSUD Dr. Soetomo.

Table 4. Relation of Type of Reconstruction to Mastication Status

\begin{tabular}{|l|l|l|l|l|l|}
\hline \multirow{2}{*}{ Reconstruction Type } & Mastication Status & Total & P-Value & OR \\
\cline { 2 - 4 } & Good (\%) & Bad (\%) & & & \\
\hline Plate & $7(30,4 \%)$ & $16(69,6 \%)$ & $23(100 \%)$ & 0.515 & 4,571 \\
\hline Plate Bone Graft & $18(66,7 \%)$ & $9(33,3 \%)$ & $27(100 \%)$ & & $(95 \%$ \\
\hline Total & $25(50 \%)$ & $25(50 \%)$ & $50(100 \%)$ & & CI: $1,383-15,109)$ \\
\hline
\end{tabular}

\section{DISCUSSION}

In this study, it was found that the highest age group was aged 21-40 years as many as 33 people $(66 \%)$, followed by ages over 41 years as many as 17 people (34\%). Based on the results of the study, the majority of genders were 26 men $(52 \%)$, followed by 24 women (48\%). A systematic study showed that the number of ameloblastoma per hospital was significantly higher in an Asian or African population with a mean age of 31.4 years with a male:female ratio of $1.5: 1$ and $90.8 \%$ of tumors located in the mandible. Another study in a Japanese population showed the mean age was 34.7 years with a male:female ratio of $1.6: 1$ and $92.6 \%$ located in the mandible. So far no studies have been found in the Indonesian population. ${ }^{6}$

Mandibular resection is part of the surgical operation for cases of benign and malignant tumors of the mandible, whereas in the case of ameloblastoma it is more radical, which consists of partial mandibulectomy and immediate reconstruction of the defect to ensure complete tumor resection, prevent a recurrence, and allow rapid and effective dental rehabilitation secure. Correct surgical planning is the key to successful management. Research conducted by Namaki showed that mandibular resection causes mastication disorders in patients so that post-resection mandibular reconstruction is needed. In addition to repairing the mandibular bone, reconstruction is necessary for the complete restoration of masticatory function, speech, and oral movement. ${ }^{7}$

In this study, it was found that the type of reconstruction used was a plate type of 23 people $(46 \%)$, and those using a plate bone graft type of 27 people $(54 \%)$. The advantage of immediate reconstruction after resection is that the patient immediately regains normal shape and function. The goals and criteria for successful mandibular reconstruction are to establish continuity, establish alveolar height, maintain bone, and improve facial contours. Meanwhile, mastication status is also seen as a measure of the success of mandibular resection and reconstruction surgery. Therefore, it is necessary to assess the masticatory status of the patient after undergoing segmental resection and mandibular reconstruction. During the post-mandibulectomy rehabilitation period, thorough consideration should also be given to the efficiency of the patient's masticatory status. $^{8,9}$

The masticatory system consists of organs and structures that mainly function in mastication. This includes the teeth and their supporting structures, the temporomandibular joint, mandible, facial muscles, tongue, lips, cheeks, oral mucosa, and the associated neurological system. Mastication is the process of breaking down food to be swallowed and digested. Mastication consists of two separate processes in which food is placed between the teeth so that it can be crushed (selection) and then broken down into particles (smoothing). Masticatory function, in general, may be affected in postmandibulectomy patients. ${ }^{10}$

In this study, the relationship test of the independent and dependent variables in the form of nominal and nominal data was carried out. Then the results of the strength of the relationship between chewing ability, types of food that can be chewed, reasons for difficulty chewing, types of foods to avoid, perceived against implant material in the jaw, time to spend food and avoiding food were found to be strong because they had a value between 0.6-0, 8. The strength of the relationship between pain when chewing 0.409 was considered sufficient. This showed that the mastication ability 
Djoko Supriyandono et.al. Comparison of mastication status in ameloblastoma patients post-mandibular segmental resection operation with LC type with mandibular reconstruction using plate and plate bone graft in RSUD Dr. Soetomo.

questionnaire can be trusted. The value obtained from the questionnaire describes the situation to be measured. ${ }^{11}$

The reliability test of the questionnaire was conducted in the form of an internal consistency test using Cronbach's alpha coefficient. This test measures the consistency of the results when measurements are repeated. According to Morgenstern (1998), Cronbach's alpha coefficient value of more than 0.8 indicates very good internal consistency, 0.6-0.8 indicates good internal consistency, 0.4-0.6 indicates adequate internal consistency and less than 0.4 shows poor internal consistency. Where the results are obtained, the Cronbach's alpha coefficient for the mastication ability questionnaire is 0.772 , which means this questionnaire has good internal consistency. ${ }^{11}$

From the data of this study, it was found that in the type of reconstruction using plates that have good mastication status as many as 7 people $(30.4 \%)$ and who have poor mastication status as many as 16 people $(69.6 \%)$, while in the type of reconstruction using plate bone graft It was found that 18 people $(66.7 \%)$ had good mastication status and 9 people $(33.3 \%)$. By using the chi-square test, it was found that there is a relationship between the type of reconstruction and mastication status with a $\mathrm{p}$-value $=0.011(\mathrm{p}<0.05)$ which means that there is a statistical relationship between the type of reconstruction and the postmandibular mastication status. Using plate bone graft had 5 times better mastication status than those using plate reconstruction $(\mathrm{OR}=0.219 ; 95 \% \mathrm{CI})$.

The results showed that reconstruction with plate bone graft had a better mastication status than patients with plate reconstruction. This plate without bone graft is indicated for short lateral segments, patients who are not undergoing resection involving soft tissue or mucosa, and patients who will not undergo radiation. The success rate for this plate reconstruction ranged from $34 \%$ in the first 6 months postoperatively to $64 \%$ at follow-up for 1 year postoperatively. On the plate with bone graft, there are several options, namely the iliac crest graft which is the main choice because its shape is almost close to the part of the mandible, and the rib graft which is widely used for condylar bone reconstruction in children and adults. However, the lack of growth of the bones varies. $^{12}$

\section{CONCLUSION}

There is a statistically significant relationship between the type of reconstruction and mastication status. An ameloblastoma patient after mandibular segmental resection surgery with an LCtype defect who underwent mandibular reconstruction using a bone graft plate had a better mastication status than the one using a plate without a bone graft.

Acknowledgement: None

Conflict of Interest: None

\section{Source of Funding: None}

\section{Ethical Approval: Approved}

\section{REFERENCES}

1. Munir, M. (2000) 'Ameloblastoma of the jaws.', Gan to kagaku ryoho. Cancer \& chemotherapy, 27 Suppl 2(September 2012), pp. 261-267.

2. Bharathwaj, S. and Arvind, A. (2004) 'Mandibular reconstruction with microvascular fibular flaps after large resections: Towards a functional and cosmetic goal', Apollo Medicine, 1(2), pp. 109-116. doi: 10.1016/s09760016(11)60235-4.

3. Namaki, S. et al. Masticatory efficiency before and after surgery in oral cancer patients : comparative study of glossectomy, marginal mandibulectomy and segmental mandibulectomy. J Oral Sci. 2004 Jun;46(2): 113-7. doi: 10.2334/josnusd. 46.113.

4. Funayama, A. et al. (2017) 'A simple technique for repositioning of the mandible by a surgical guide prepared using a three- 
Djoko Supriyandono et.al. Comparison of mastication status in ameloblastoma patients post-mandibular segmental resection operation with LC type with mandibular reconstruction using plate and plate bone graft in RSUD Dr. Soetomo.

dimensional model after segmental mandibulectomy', Maxillofacial Plastic and Reconstructive Surgery, 39(1). doi: 10.1186/s40902-017-0113-5.

5. Tsuga, K. et al. (1998) 'Self-assessed masticatory ability in relation to maximal bite force and dental state in 80-year-old subjects', Journal of Oral Rehabilitation, 25(2), pp. 110-116. doi: 10.1046/j.13652842.1998.00233.x.

6. Ruslin, M. et al. (2018) 'The Epidemiology, treatment, and complication of ameloblastoma in East-Indonesia: 6 years retrospective study', Medicina oral, patologia oral y cirugia bucal, 23(1), pp. e54-e58. doi: 10.4317/medoral.22185.

7. Bianchi, B. et al. (2013) 'Mandibular Resection and Reconstruction in the Management of Extensive Ameloblastoma', Journal of Oral and Maxillofacial Surgery, 71(3), pp. 528-537. doi: 10.1016/j.joms.2012.07.004.

8. Kumar, B. P. et al. (2016) 'Mandibular Reconstruction: Overview', Journal of maxillofacial and oral surgery. 2015/04/19, 15(4), pp. 425-441. doi: 10.1007/s12663015-0766-5.

9. Mustafa, A. A., Raad, K. and Mustafa, N. S. (2015) 'Effect of proper oral rehabilitation on general health of mandibulectomy patients', Clin Case Rep. pp. 907-911. doi: 10.1002/ccr3.373.

10. Miho Kamiyama et al. (2010) 'Validity and reliability of a Self-Implementable method to evaluate masticatory performance: Use of color-changeable chewing gum and a color scale', J Prosthodont Res. 54, pp. 2428. doi: 10.1016/j.jpor.2009.08.001.

11. Hanin, I., Kusdhany, L. S. and Gita, F. (2012) 'Hubungan kemampuan mastikasi (analisis menggunakan alat ukur kemampuan mastikasi) dengan kualitas hidup wanita pra-lansia dan lansia. Thesis.', Dept. Prostodonsia, Universitas Indonesia, pp. 37-9, 58-9.

12. Torroni, A. et al. (2015) 'Mandibular Reconstruction With Different Techniques': Journal of Craniofacial Surgery, 26(3), pp. 885-890. doi: 10.1097/SCS.0000000000001411.

How to cite this article: Supriyandono D, Wibowo MD, Susilo DH et.al. Comparison of mastication status in ameloblastoma patients post-mandibular segmental resection operation with LC type with mandibular reconstruction using plate and plate bone graft in RSUD Dr. Soetomo. International Journal of Research and Review. 2021; 8(7): 375-380. DOI: https://doi. org/10.52403/ijrr.20210753 